\title{
Impact of Brief and Sequential Exposure to Nystatin on the Germ Tube Formation and Cell Surface Hydrophobicity of Oral Candida Albicans Isolates from Human Immunodeficiency Virus-Infected Patients
}

\author{
Arjuna N.B. Ellepola ${ }^{a}$ Lakshman P. Samaranayake ${ }^{b}$ \\ ${ }^{a}$ Department of Bioclinical Sciences, Faculty of Dentistry, Kuwait University, Safat, Kuwait; ${ }^{b}$ Oral Biosciences, \\ Faculty of Dentistry, University of Hong Kong, Hong Kong, SAR, China
}

\author{
Key Words \\ Candida albicans . Cell surface hydrophobicity . \\ Germ tubes · Nystatin
}

elucidate the possible pharmacodynamic mechanisms by which nystatin might operate in vivo in the modulation of candidal virulence.

(c) 2014 S. Karger AG, Basel

\begin{abstract}
Objective: To evaluate the impact of brief and sequential exposure to nystatin on the germ tube formation and cell surface hydrophobicity of oral isolates of Candida albicans obtained from patients infected with human immunodeficiency virus (HIV). Materials and Methods: After determining the minimum inhibitory concentration of nystatin, 10 oral isolates of C. albicans from 10 different HIV-infected patients were briefly ( $1 \mathrm{~h}$ ) and sequentially ( 10 days) exposed to subtherapeutic concentrations of nystatin. Following a subsequent drug removal, the germ tube formation and cell surface hydrophobicity of these isolates were determined via a germ tube induction assay and an aqueous hydrocarbon assay, respectively. The data obtained from these assays for the control (unexposed to nystatin) and nystatin-exposed isolates were analyzed using Student's t tests. Results: The mean percentage reduction in the germ tube formation and cell surface hydrophobicity of the nystatin-exposed isolates compared to the controls was $30.12 \pm 1.99(p<0.001)$ and $29.65 \pm 2.33(p<0.001)$, respectively. Conclusion: These data
\end{abstract}

\section{Introduction}

More than $90 \%$ of human immunodeficiency virus (HIV)-infected individuals develop oral candidosis at some point during the disease, and it is by far the commonest oral manifestation in these patients. In HIV-infected patients, persistent debilitating pseudomembranous oral mucosal disease has been linked to oral Candida and has been postulated to be intimately associated with the level of host immunosuppression. Also, oral candidosis and the amount of Candida present have been postulated to be predictive of the HIV disease progression and viral load [1]. Among all Candida species, Candida albicans is considered the most virulent and pervasive fungal pathogen implicated in oral candidosis.

Multiple factors have been implicated in the potentiation of the C. albicans pathogenicity, and its adherence to host mucosal surfaces is a major determinant of successful microbial colonization and subsequent infection [2].

\begin{tabular}{ll}
\hline KARGER & $\begin{array}{l}\text { ๑ 2014 S. Karger AG, Basel } \\
1011-7571 / 14 / 0234-0307 \$ 39.50 / 0 \quad \text { Karger }\end{array}$ \\
E-Mail karger@karger.com & $\begin{array}{l}\text { This is an Open Access article licensed under the terms of the } \\
\text { Www.karger.com/mpp }\end{array}$ \\
& $\begin{array}{l}\text { Creative Commons Attribution-NonCommercial 3.0 Un- } \\
\text { ported license (CC BY-NC) (www.karger.com/OA-license), } \\
\text { applicable to the online version of the article only. Distribu- } \\
\text { tion permitted for non-commercial purposes only. }\end{array}$
\end{tabular}

Dr. Arjuna Ellepola, BDS, PhD, FIBiol Department of Bioclinical Sciences Faculty of Dentistry, Kuwait University PO Box 24923, Safat 13110 (Kuwait) E-Mail arjuna@hsc.edu.kw 
Adhesion enables the organisms to avoid dislodgement due to the cleansing action of mucosal secretions and facilitates infection. Germ tubes (GT), which mark the onset of hyphal growth, are a biological trait that has been implicated in the pathogenesis of oral candidosis, as these cylindrical extrusions are known to facilitate yeast adherence to epithelial cells and impart resistance to phagocytic killing [3, 4]. Furthermore, GT tend to promote the aggregation of yeast cells and bridging of adjacent hyphal elements, thereby bringing a large battery of organisms in intimate contact with the oral epithelium [5]. Candida hyphae have also been shown to penetrate dentinal tubules along the cracks of tooth surfaces, enabling the organisms to invade dental hard tissues [6]. In addition, microbial cell surface hydrophobicity (CSH), which contributes to hydrophobic interactions between cells and surfaces, is thought to be a nonbiological factor associated with the adherence of Candida to inert surfaces [7]. Studies have also shown that hydrophobic yeasts are more virulent than their hydrophilic counterparts $[8,9]$. Significant correlations between CSH and candidal adhesion to buccal epithelial cells and denture acrylic surfaces have also been previously reported $[10,11]$.

Nystatin is a widely available antifungal agent for the topical treatment of oral candidosis. However, the diluting effect of saliva and the cleansing effect of the oral musculature in the oral cavity tend to reduce the availability of topically applied antimycotics below that of effective therapeutic concentrations, thereby compromising their therapeutic efficacy $[12,13]$. Hence, the opportunistic yeasts may undergo brief and sequential exposure to topically applied antifungal drugs during therapy, a scenario which is all too common in the niches of the oral cavity $[12,13]$. To our knowledge, there is no information on the impact of brief and sequential exposure to nystatin on the colonization traits of oral C. albicans isolates obtained from HIV-infected patients. Thus, the aim of this study was to determine the effect of such exposure to nystatin on the GT formation and CSH of oral isolates of C. albicans from $\mathrm{HIV}$-infected patients.

\section{Subjects and Methods}

\section{Organisms}

The following oral C. albicans isolates were studied: $\mathrm{HK} 1 \mathrm{Kd}$ (N1), HK3 Ob (N2), HK4 Rb (N3), HK5 Sd (N4), HK6 Sc (N5), HK8 Ca (N6), HK9 Tb (N7), HK10 Od (N8), HK36 Sc (N9), and HK39 Re (N10). These isolates were derived from 10 different HIV-infected patients attending the AIDS Unit of the Department of Health (Hong Kong, SAR, China). C. albicans ATCC 90028 was used as the reference strain. Initially, all of the yeast isolates were tested for GT formation and thereafter they were identified by their carbohydrate assimilation profiles obtained using API 20C Aux yeast identification kits (API System, Vercieu, France) at the Prince Philip Dental Hospital (Hong Kong, SAR, China). Stock cultures were maintained at $-20^{\circ} \mathrm{C}$. After recovery, these were maintained on Sabouraud's dextrose agar (SDA), stored at $4-6^{\circ} \mathrm{C}$, during the experimental period.

\section{Antifungal Agents and Media}

As described previously [12-15], nystatin (Sigma, St. Louis, Mo., USA) was dissolved in dimethyl sulfoxide (DMSO) and absolute ethanol (3:2 ratio), respectively, and was initially prepared as a $10,000-\mu \mathrm{g}$ solution and stored at $-20^{\circ} \mathrm{C}$ before use. It was thereafter suspended in the following medium during the period of exposure to yeasts $(1 \mathrm{~h})$ : Rosewell Park Memorial Institute (RPMI) 1640 medium buffered with $0.165 \mathrm{M}$ morpholinopropanesulfonic acid (MOPS) containing L-glutamine and lacking sodium bicarbonate (Sigma) in 1 liter of sterile distilled water adjusted to a $\mathrm{pH}$ of 7.2 and filter sterilized [12-15]. This liquid (RPMI) was stored at $2-8^{\circ} \mathrm{C}$. The stock solution was used to obtain the drug concentrations [i.e. $2 \times$ the minimum inhibitory concentration (MIC)] used in the experiments.

Since nystatin was dissolved in DMSO and absolute ethanol, equivalent amounts of the latter chemicals were tested initially as was done in previous studies using the same isolates to ascertain whether they had an effect on the isolates tested. Minute amounts of the chemicals used in this study did not have any effect on yeast survival/growth when compared to the controls.

\section{Determination of the MIC}

Prior to the brief and sequential exposure to nystatin, the MIC values of nystatin were determined via the broth dilution technique as described previously [12-15] by performing 2 -fold serial dilutions of the drug in microtiter plates using an inoculum of 1-5 $\times 10^{5} \mathrm{CFU} / \mathrm{ml}$. The MIC was determined visually and spectrophotometrically at $595 \mathrm{~nm}$ following $24 \mathrm{~h}$ of incubation at $37^{\circ} \mathrm{C}$. The MIC was defined as the lowest concentration of the drug that inhibited the growth of yeast cells, as indicated by the absence of turbidity (optically clear). The MIC was read independently by two independent observers. C. albicans ATCC 90028 was used as a reference strain. All experiments were repeated on two separate occasions with duplicate determinations on each occasion.

\section{Preparation of the Cell Suspension for the GT Assay and the}

Relative CSH Assay

A previously described method was used for this purpose [1215]. Briefly, yeast cells maintained on SDA were inoculated onto fresh plates and incubated overnight at $37^{\circ} \mathrm{C}$ for $24 \mathrm{~h}$ prior to use. The organisms were harvested and a cell suspension was prepared in sterile PBS with a $\mathrm{pH}$ of 7.4 to an optical density (OD) of 1.5 at $520 \mathrm{~nm}$. One milliliter of this cell suspension was added to tubes containing $4 \mathrm{ml}$ of RPMI broth (control) and $4 \mathrm{ml}$ of RPMI/drug solution (test), in which the drug concentrations were twice the MIC values. This yielded a cell suspension of $10^{6}$ cells $/ \mathrm{ml}$ in each assay tube. The tubes were then incubated at $37^{\circ} \mathrm{C}$ for a period of $1 \mathrm{~h}$ in a rotary incubator. Following this limited exposure, the drugs were removed by 2 cycles of dilution with sterile PBS and centrifugation for $10 \mathrm{~min}$ at 3,000 g. Afterwards the supernatant was completely decanted and the pellets were resuspended in $5 \mathrm{ml}$ 
Table 1. Impact of brief (1 h) and sequential (10 days) exposure to nystatin $(2 \times$ the initial MIC) on the susceptibility of oral C. albicans isolates to this drug

\begin{tabular}{lll}
\hline Isolate & $\begin{array}{l}\text { Initial MIC, } \\
\mu \mathrm{g} / \mathrm{ml}\end{array}$ & $\begin{array}{l}\text { MIC following exposure } \\
\text { to nystatin, } \mu \mathrm{g} / \mathrm{ml}\end{array}$ \\
\hline $\mathrm{N} 1$ & 0.78 & 1.56 \\
$\mathrm{~N} 2$ & 0.78 & 1.56 \\
$\mathrm{~N} 3$ & 1.56 & 1.56 \\
$\mathrm{~N} 4$ & 1.56 & 1.56 \\
$\mathrm{~N} 5$ & 1.56 & 0.78 \\
$\mathrm{~N} 6$ & 1.56 & 0.78 \\
$\mathrm{~N} 7$ & 1.56 & 1.56 \\
$\mathrm{~N} 8$ & 0.78 & 1.56 \\
$\mathrm{~N} 9$ & 1.56 & 0.78 \\
$\mathrm{~N} 10$ & 1.56 & 0.78 \\
\hline
\end{tabular}

of sterile PBS. One hundred microliters of this cell suspension were then inoculated onto SDA plates and incubated at $37^{\circ} \mathrm{C}$ for $24 \mathrm{~h}$. Thereafter, the organisms were harvested and once again exposed to the drug as mentioned previously. This procedure was performed for 10 consecutive days, after which the cultures of the drug-treated Candida (test) and the Candida unexposed to nystatin (control) were inoculated onto SDA plates and incubated at $37^{\circ} \mathrm{C}$ for $24 \mathrm{~h}$. Thereafter, these cultures were maintained on SDA and stored at $4-6^{\circ} \mathrm{C}$ prior to being used for the GT and $\mathrm{CSH}$ assays. Hence, this procedure allowed the Candida exposed to the drug to recover and grow after the final treatment with nystatin.

The aforementioned procedure for drug removal has been shown to reduce the concentration of the drug by as much as 10,000 -fold, thereby minimizing any carryover effect of the drug following its removal [12-18]. Viable counts of the control and the test were performed after each procedure of drug removal. As the procedure of drug removal effectively eliminated any carryover effect, there was virtually no difference between the viable counts of the control and tests following exposure to the already diluted subtherapeutic concentrations of the drug as observed in previous studies [12-18].

\section{Microscopic Quantification of GT Forming Cells (GT Assay)}

A previously used method for GT induction was employed [15, 16]. RPMI 1640 medium with L-glutamine (Sigma) was chosen for the assay because it effectively induces GT formation. Yeast suspensions of the control and test (following brief and sequential exposure) were prepared in sterile PBS at $520 \mathrm{~nm}$ to an OD of 1.5. For GT induction, $250 \mu \mathrm{l}$ of the yeast suspensions of the control and test (following brief and sequential exposure) were added to $1 \mathrm{ml}$ of RPMI 1640 medium with L-glutamine and incubated at $37^{\circ} \mathrm{C}$ for $90 \mathrm{~min}$.

Then, the tube was vortex mixed for $10 \mathrm{~s}$ and a drop of each cell suspension was placed on a Neubauer hemocytometer chamber and covered with a coverslip for GT quantification. Thereafter, 300 yeast cells in contiguous fields were counted (under a $\times 40$ magnification) and the percentage of GT-forming cells was calculated. The following previously used criteria were employed for counting $[15,16]$ : (a) only yeast cells with a GT, without constriction at the junction between the cell and the elongation, were counted; (b) clumped cells with GT were excluded, and (c) pseudohypha-forming yeast cells were excluded.

\section{Relative CSH Assay}

A biphasic aqueous hydrocarbon assay previously used for the assessment $\mathrm{CSH}$ in oral Candida species was used in the current study $[14,17,18]$. In brief, $5 \mathrm{ml}$ of the control and test (following brief and sequential exposure) yeast suspensions were adjusted to an OD of $0.442-0.448$ at $520 \mathrm{~nm}$ to obtain a cell concentration of McFarland standard 7.0 (Beckman DU 530 spectrophotometer; Life Science, USA). For each organism tested (with and without exposure to nystatin), $2.5-\mathrm{ml}$ volumes of suspension were added to 2 sterile glass test tubes $(16 \times 150 \mathrm{~mm} ; 20 \mathrm{ml})$, representing 1 test and 1 control. Xylene $(0.5 \mathrm{ml})$ was added to each test suspension. The test and controls were placed in a water bath at $37^{\circ} \mathrm{C}$ for 10 min to equilibrate; they were then taken and vortex mixed for $30 \mathrm{~s}$ and returned to the water bath for a further $30 \mathrm{~min}$ to allow the immiscible xylene and aqueous phases to separate. The lower, aqueous phase of the sample was carefully removed using a pipette and transferred to a clean test tube. Any traces of contaminating xylene that may have been carried over in the pipette or bound to the yeast were removed by bubbling air through the suspension at a rate of $180 \mathrm{ml} / \mathrm{min}$ for $2 \mathrm{~min}$. The absorbance was measured as before at $520 \mathrm{~nm}$ (Beckman DU 530 spectrophotometer; Life Science) after vortex mixing for $5 \mathrm{~s}$. Hydrophobicity was expressed as the percentage reduction in OD of the test suspension compared to the control $[14,17,18]$. Thus, the greater the change in absorbance was, the greater the shift in yeasts from the bulk medium to the interface was (i.e. the more hydrophobic the yeast strain). Suspensions without xylene were used as the negative controls.

All experiments were repeated on 3 separate occasions, with duplicate determinations on each occasion.

\section{Statistical Analysis}

The data obtained from the GT and CSH assays performed thrice in duplicate were analyzed using Student's t tests (SPSS version 19.0), which treat one group as a control (unexposed to nystatin) and compare the other group (exposed to nystatin) against it. $\mathrm{p}<0.05$ was considered statistically significant.

\section{Results}

The MIC $(\mu \mathrm{g} / \mathrm{ml})$ values of the 10 isolates of C. albicans to nystatin prior to exposure to nystatin and following brief and sequential exposure to this drug are given in table 1. In both instances, the MIC values ranged from 0.78 to 1.56 . Hence, all isolates were susceptible to nystatin, with no apparent change in MIC values. These values remained within the susceptible range for this drug.

The mean percentage of GT-positive cells in the 10 C. albicans isolates unexposed to nystatin and following brief and sequential exposure to this antifungal, drug removal, and the subsequent observation of GT formation 
Table 2. GT-positive cells and mean reduction in the GT formation of oral C. albicans isolates following brief $(1 \mathrm{~h})$ and sequential $(10$ days) exposure to nystatin $(2 \times$ the initial MIC)

\begin{tabular}{llll}
\hline Isolate & $\begin{array}{l}\text { GT-positive cells in } \\
\text { unexposed controls } \\
\%\end{array}$ & $\begin{array}{l}\text { GT-positive cells } \\
\text { following exposure } \\
\text { to nystatin }{ }^{\mathrm{a}}, \%\end{array}$ & $\begin{array}{l}\text { Reduction in } \\
\text { GT formation } \\
\%\end{array}$ \\
\hline N1 & $26.42 \pm 1.24$ & $18.34 \pm 0.71$ & 30.58 \\
N2 & $29.54 \pm 1.00$ & $24.96 \pm 0.67$ & 15.50 \\
N3 & $29.78 \pm 0.60$ & $21.72 \pm 0.94$ & 27.07 \\
N4 & $32.16 \pm 1.13$ & $20.25 \pm 0.62$ & 37.03 \\
N5 & $28.32 \pm 0.66$ & $18.76 \pm 0.64$ & 33.76 \\
N6 & $24.58 \pm 0.64$ & $16.14 \pm 0.66$ & 34.34 \\
N7 & $31.23 \pm 1.01$ & $20.76 \pm 0.68$ & 33.53 \\
N8 & $21.59 \pm 0.96$ & $14.75 \pm 1.17$ & 31.68 \\
N9 & $22.36 \pm 0.86$ & $14.93 \pm 1.07$ & 33.23 \\
N10 & $30.78 \pm 0.54$ & $23.26 \pm 0.42$ & 24.43 \\
\hline Mean & 27.68 & 19.38 & 30.12 \\
SEM & 1.19 & 1.09 & 1.99 \\
p & & & $<0.001$ \\
\hline
\end{tabular}

${ }^{\text {a }}$ Mean data \pm SEM of 3 experiments done in duplicate.

${ }^{\mathrm{b}}$ Obtained by comparing the mean values of drug-exposed isolates to those of unexposed isolates. was $27.68 \pm 1.19$ (range $21.59-32.16)$ and $19.38 \pm 1.09$ (range 14.75-24.96), respectively, and the mean percentage reduction was $30.12 \pm 1.99 \%$ (range 15.5-37.03; p < 0.001; table 2).

The mean $\mathrm{CSH}$ of the $10 \mathrm{C}$. albicans isolates unexposed to nystatin and following brief and sequential exposure to nystatin, drug removal, and the subsequent determination of $\mathrm{CSH}$ via a biphasic aqueous hydrocarbon assay was $16.89 \pm 1.04$ (range 12.36-21.32) and $11.82 \pm$ 0.74 (range 8.56-14.93), respectively, and the mean percentage reduction was $29.65 \pm 2.33 \%$ (range 18.93-40.11; $\mathrm{p}<0.001$; table 3 ).

\section{Discussion}

In this study, the MIC values of nystatin before and after brief and sequential exposure to this drug were within the range of the reference strain $(0.78-1.56 \mu \mathrm{g} / \mathrm{ml})$, which implied that the isolates tested were susceptible to the drug despite multiple episodes of drug exposure. Furthermore, these values were within the MIC range obtained in previous investigations of $C$. albicans isolates $[12,14,15]$. Therefore, it could be speculated that such brief $(1 \mathrm{~h})$ and sequential (10 days) exposure to subthera-
Table 3. Relative $\mathrm{CSH}$ and mean percentage reduction in the $\mathrm{CSH}$ of oral C. albicans isolates following brief $(1 \mathrm{~h})$ and sequential $(10$ days) exposure to nystatin ( $2 \times$ the initial MIC)

\begin{tabular}{llcc}
\hline Isolate & $\begin{array}{l}\text { CSH of } \\
\text { unexposed } \\
\text { controls }^{\mathrm{a}}\end{array}$ & $\begin{array}{l}\text { CSH following } \\
\text { exposure to } \\
\text { nystatin }^{\mathrm{a}}\end{array}$ & $\begin{array}{l}\text { Reduction in } \\
\text { CSH }^{\mathrm{b}} \%\end{array}$ \\
\hline N1 & $19.67 \pm 0.52$ & $11.78 \pm 0.88$ & 40.11 \\
N2 & $14.04 \pm 1.32$ & $8.56 \pm 0.36$ & 39.03 \\
N3 & $19.58 \pm 0.40$ & $14.58 \pm 1.27$ & 25.53 \\
N4 & $16.26 \pm 0.59$ & $10.57 \pm 0.62$ & 34.99 \\
N5 & $16.78 \pm 0.76$ & $13.52 \pm 0.71$ & 19.42 \\
N6 & $12.36 \pm 0.96$ & $10.02 \pm 0.58$ & 18.93 \\
N7 & $15.78 \pm 0.69$ & $10.68 \pm 0.63$ & 32.32 \\
N8 & $20.56 \pm 0.91$ & $14.26 \pm 1.37$ & 30.64 \\
N9 & $21.32 \pm 1.10$ & $14.93 \pm 1.36$ & 29.97 \\
N10 & $12.52 \pm 1.03$ & $9.32 \pm 0.51$ & 25.56 \\
\hline Mean & 16.89 & 11.82 & 29.65 \\
SEM & 1.04 & 0.74 & 2.33 \\
p & & & $<0.001$ \\
\hline
\end{tabular}

${ }^{\text {a }}$ Mean data \pm SEM of 3 experiments performed in duplicate.

${ }^{\mathrm{b}}$ Obtained by comparing the mean values of drug-exposed isolates to those of unexposed isolates. peutic concentrations of nystatin does not have a significant impact on the susceptibility of the isolates and is unlikely to induce the development of drug resistance despite such exposure.

The reduction in GT formation of $30.12 \%$ following limited and sequential exposure to nystatin seen in this study may be related to the mechanism of action of this drug on the Candida cell wall. Polyenes bind avidly to the sterol components in the cell wall of Candida, thereby making it more permeable and leading to the impairment of barrier function, the leakage of cellular components, and metabolic disruption $[12,13]$. Also, it has been suggested that the formation of sterols or their precursors may be inhibited by polyenes $[12,13]$. Other investigations $[15,19]$ have shown internally collapsed cells with an intact cell wall that leave behind 'ghosts-like' cells and deflated Candida cells following exposure to subtherapeutic concentrations of nystatin [15]. Studies have also demonstrated dynamic changes in the ultrastructural features of the cell wall during morphogenic transformation to GT and have shown that the cell wall of GT possesses a stratification comparable to that of the blastospore wall [19]. Therefore, it is not surprising that nystatin-induced changes in the cell wall structure of $C$. albicans isolates affect active budding and multiplication, thus suppress- 
ing the GT formation following brief and sequential exposure to nystatin.

Similar to that in GT formation, a reduction in CSH of $29.65 \%$ following a limited and sequential exposure to nystatin was also seen in this study. The microbial structures that contribute to $\mathrm{CSH}$ include outer membrane proteins, lipoproteins, phospholipids, lipopolysaccharides, and fimbriae [20]. Thus, drugs that modify these structural features have been shown to reduce the $\mathrm{CSH}$ of microbes [21]. In the case of C. albicans, it has been shown that $\mathrm{CSH}$ correlates with the concentration of fibrils in the exterior layer of the cell wall. Hence, the observed reduction in CSH elicited by nystatin in C. albicans may be related to the aforementioned pharmacodynamics of nystatin on the cell wall of $C$. albicans. Therefore, it is reasonable to speculate that by affecting the cell wall structure nystatin may be capable of suppressing the CSH of this Candida species.

In previous studies, we demonstrated that a single brief exposure to nystatin induced a $97.68 \%$ reduction in GT formation and a $27.14 \%$ reduction in CSH in oral isolates of C. albicans $[14,15]$. This almost complete abrogation of GT formation ( $97.68 \%$ reduction) may have been due to the fact that these studies were conducted soon after drug removal, when the isolates were in a state of nystatin-induced metabolic shock, whereas the current study was conducted after a recovery period of these isolates, resulting in less of an impact on GT formation $(30.12 \%)$. In contrast, there was virtually no difference in the impact of nystatin on CSH between these previous studies (27.14\% reduction) and the current study (29.65\% reduction), which may be due to the lower sensitivity of nystatin on nonbiological traits such as $\mathrm{CSH}$ compared to biological attributes such as GT formation. In fact, a re- cent study on the effect of nystatin on the adhesion attributes of $C$. dubliniensis isolates failed to show a relationship between these two adhesion characteristics following exposure to nystatin [22]. Irrespectively of these differences, it is reasonable to venture that by affecting the cell wall structure nystatin may be capable of subduing both biological (GT formation) and nonbiological (CSH) adhesion traits of Candida species.

The resistance of $C$. albicans to azoles and echinocandin antifungal agents has been documented [23], which may have important implications for antifungal therapy in the management of oral candidosis in HIV infection and indicates the need for alternative therapies. In this context, the current findings enhance the usage of nystatin as a mainstay topical agent in the management of oral candidosis.

\section{Conclusion}

The current results show that brief and sequential exposure to nystatin is capable of modulating C. albicans adhesion by reducing the GT formation as well as its $\mathrm{CSH}$ and thereby adds further credence to the effectiveness of nystatin against these colonization attributes of $C$. albicans.

\section{Acknowledgments}

The technical support of Ms. Joyce Yau and Mr. Simon Lee (Oral Biosciences, Faculty of Dentistry, Prince Philip Dental Hospital, University of Hong Kong, Hong Kong, SAR, China) is gratefully acknowledged.

\section{References}

1 McCullough M, Patton LL, Coogan M, et al: New approaches to Candida and oral mycotic infections: workshop 2A. Adv Dent Res 2011; 23:152-158

2 Samaranayake LP, Ellepola AN: Studying Candida albicans adhesion; in An YH, Friedman RJ (eds): Handbook of Bacterial Adhesion. Clifton, Humana, 2000, pp 527-540.

3 Richardson MD, Smith H: Production of germ tubes by virulent and attenuated strains of Candida albicans. J Infect Dis 1981;144: 565-569.
4 Tronchin G, Bouchara JP, Robert R, et al: Adherence of Candida albicans germ tubes to plastic: ultrastructural and molecular studies of fibrillar adhesins. Infect Immun 1988;56: 1987-1993.

-5 Sobel JD, Muller G, Buckley HR: Critical role of germ tube formation in the pathogenesis of candidal vaginitis. Infect Immun 1984;44: 576-580.

-6 Sen BH, Safavi KE, Spångberg LS: Colonization of Candida albicans on cleaned human dental hard tissues. Arch Oral Biol 1997;42: 513-520.

$\checkmark 7$ Klotz SA, Drutz DJ, Zajic JE: Factors governing adherence of Candida species to plastic surfaces. Infect Immun 1985;50:97-101.
8 Hazen KC, Plotkin BJ, Klimas DM: Influence of growth conditions on cell surface hydrophobicity of Candida albicans and Candida glabrata. Infect Immun 1986;54:269-271.

-9 Hazen KC, Hazen BW: Surface hydrophobic and hydrophilic protein alterations in Candida albicans. FEMS Microbiol Lett 1993;107: 83-87.

10 Panagoda GJ, Samaranayake LP: The relationship between the cell length, adhesion to acrylic and relative cell surface hydrophobicity of Candida parapsilosis. Med Mycol 1998; 36:373-378.
Nystatin and Adhesion Attributes of C. albicans in HIV-Infected Patients 
11 Panagoda GJ, Ellepola AN, Samaranayake LP: Adhesion to denture acrylic surfaces and relative cell-surface hydrophobicity of Candida parapsilosis and Candida albicans. APMIS 1998;106:736-742.

12 Ellepola AN, Samaranayake LP: The in vitro post-antifungal effect of nystatin on Candida species of oral origin. J Oral Pathol Med 1999; 28:112-116.

13 Ellepola AN: Amphotericin B-induced in vitro postantifungal effect on Candida species of oral origin. Med Princ Pract 2012;21:442446.

14 Ellepola AN, Samaranayake LP: The effect of limited exposure to antimycotics on the relative cell-surface hydrophobicity and the adhesion of oral Candida albicans to buccal epithelial cells. Arch Oral Biol 1998;43:879887.
15 Ellepola AN, Samaranayake LP: The effect of limited exposure to antifungal agents on the germ tube formation of oral Candida albicans. J Oral Pathol Med 1998;27:213-219.

16 Ellepola AN, Joseph BK, Khan ZU: Effects of subtherapeutic concentrations of chlorhexidine gluconate on germ tube formation of oral Candida. Med Princ Pract 2012;21:120124.

17 Ellepola AN, Joseph BK, Khan ZU: Cell surface hydrophobicity of oral Candida dubliniensis isolates following limited exposure to sub-therapeutic concentrations of chlorhexidine gluconate. Mycoses 2013;56:82-88.

18 Ellepola AN, Joseph BK, Khan ZU: Changes in the cell surface hydrophobicity of oral Candida albicans from smokers, diabetics, asthmatics, and healthy individuals following limited exposure to chlorhexidine gluconate. Med Princ Pract 2013;22:250-254.

19 Cassone A, Simonetti N, Strippoli V: Ultrastructural changes in the wall during germtube formation from blastospores of Candida albicans. J Gen Microbiol 1973;77:417-426.
20 Shibl AM, Ramadan MA, Tawfik AK: Postantibiotic effect of roxithromycin on streptolysin O production, hydrophobicity, and bactericidal activity of PMNL by Streptococcus pyogenes. Diagn Microbiol Infect Dis 1994;20: 7-11.

21 Ramadan MA, Tawfik AF, Shibl AM, et al: Post-antibiotic effect of azithromycin and erythromycin on streptococcal susceptibility to phagocytosis. J Med Microbiol 1995;42: 362-366.

22 Ellepola AN, Joseph BK, Chandy R, Khan $\mathrm{ZU}$ : The postantifungal effect of nystatin and its impact on adhesion attributes of oral Candida dubliniensis isolates. Mycoses 2014;57: 56-63.

23 Pfaller MA: Antifungal drug resistance: mechanisms, epidemiology, and consequences for treatment. Am J Med 2012;125:S3-S13. 